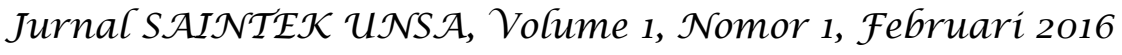

\title{
ANALISIS KONSTRUKSI INSTALASI PENGOLAHAN AIR LIMBAH (IPAL) KOMUNAL UNTUK DAERAH PADAT PENDUDUK DI KELURAHAN BRANG BARA KECAMATAN SUMBAWA SUMBAWA BESAR
}

Oleh : Isra Junna, Zulkarnaen, Alfian Rusdi.

\begin{abstract}
ABSTRAK
Instalasi Pengolahan Air Limbah (IPAL) komunal merupakan salah satu solusi untuk mengatasi masalah pencemaran lingkungan, dengan dibangunya bangunan konstruksi IPAL itu sendiri dapat mengurangi masalah pencemaran lingkungan hususnya masalah air limbah, untuk melalukan pembangunan konstruksi IPAL komunal tentunya melakukan beberapa proses analisis, baik pengumpulan data primer maupun skunder. data dapat diolah, dengan hasil olahan data muncullah desain konstruksi IPAL komunal yang berkapasitas 216.98 jiwa dengan debit Air limbah $20.83008 \mathrm{~m}^{3} /$ hari.

Untuk mendapat semua data yang diperlukan tentunya menggunakan metode, yaitu metode analisis diskriptif kuantatif dan metode analisis. Metode analisis diskriftif kuantatif digunakan untuk menggambarkan parameterparameter yang digunakan dalam menjawab permasalahan pertama seperti kepadatan penduduk, sumber air bersih, kemiringan lereng dan topografi, metode analisis spasial digunakan untuk menentukan alternative lokasi IPAL komunal yang layak berdasarkan input data, jarak wilayah pelayanan, jarak dari sumber air bersih.

Hasil olahan dari semua data dapat ditetapkan bahwa bangunan konstruksi IPAL yang dibangun tahun 2012 masih belum efisien pengolahannya dengan jumlah penduduk 178 jiwa, dengan melakukan analisis ulang dari tahun 2012-2022 didapatkan hasil analisis sebagai berikut: Pada bak Settler dari 1 meter pada bak pertama dan 0.6 meter pada bak kedua diubah menjadi 1.6 meter pada bak pertama dan 0.8 meter pada bak kedua, bak Anaerobic Baffled Reactor ( $A B R$ ) dari 0.7 meter diubah menjadi 0.8 meter dan jumlah kompartemen 4 bak, bak Anaerobic Filter (AF) dari 1.1 meter diubah menjadi 1.3 meter tentunya dengan perubahan yang sangat signifikan dan konstruksi IPAL tersebut dapat menampung atau mengelolah Air limbah sebesar $20.83008 \mathrm{~m}^{3} /$ hari.
\end{abstract}

Kata kunci : Analisis, Konstruksi, IPAL, Komunal.

\section{PENDAHULUAN}

Indonesia merupakan Negara kepulauan dengan populasi penduduk tertinggi keempat di dunia yang mana jumlah penduduknya mencapai 251.160,124 jiwa dengan luas wilayah 1.921,569 kilometer persegi sehingga kepadatan penduduk rata-rata per satu kilometer persegi sebesar 130.705,754 


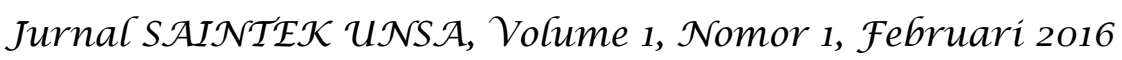

jiwa. Kabupaten Sumbawa dengan jumlah penduduk 501.138 jiwa dengan luas wilayah 6.643,98 kilometer persegi. Dari data diatas peneliti akan melakukan pengkajian berkaitan dengan hasil limbah per satu jiwa setiap hari pada permukiman di bantaran sungai Brang Bara yang akan membawa dampak pencemaran sungai.

Di Kecamatan Sumbawa mengalir 1(satu) sungai besar, yaitu sungai Brang Bara, perkembangan Kecamatan Sumbawa yang semakin cepat menyebabkan rendahnya kualitas sanitasi dan permasalahan drainase di daerah tersebut. Berdasarkan kenyataan yang telah diuraikan dalam latar belakang tersebut, penulis tertarik untuk melakukan penelitian dengan judul "ANALISIS KONSTRUKSI INSTALASI PENGOLAHAN AIR LIMBAH (IPAL) KOMUNAL, DAERAH PADAT PENDUDUK DI KELURAHAN BRANG BARA, KECAMATAN SUMBAWA, SUMBAWA BESAR."

\section{METODE PENELITIAN}

Analisis yang digunakan pada penelitian ini adalah analisis deskriptif kuantitatif dan analisis spasial. Metode analisis deskriptif kuantitatif digunakan untuk menggambarkan parameter-parameter yang digunakan dalam menjawab permasalahan pertama, parameter-parameter tesebut adalah kepadatan penduduk, air tanah dangkal, kemiringan lereng, topografi dan sumber air bersih. Sedangkan analisis spasial digunakan untuk menentukan alternatif lokasi IPAL komunal yang layak berdasarkan input data jarak wilayah pelayanan, jarak dari sumber air bersih, jarak dari pusat permukiman, tata guna lahan, kemiringan lereng, dan jarak dari jalan.

\section{HASIL DAN PEMBAHASAN}

\section{A. Pengertian IPAL komunal}

Menurut Parker sebagaimana dikuti oleh Abdul Wahab ( 2008 ), kebijakan adalah suatu tujuan tertentu atau serangkaian tindakan yang dihasilkan oleh pemerintah pada waktu tertentu dalam kaitan dengan subyek atau sebagai respon terhadap keadaan yang kritis. Menurut Dye ( 1981 ) dan Anderson (1979) dalam Subarsono ( 2008 ). 


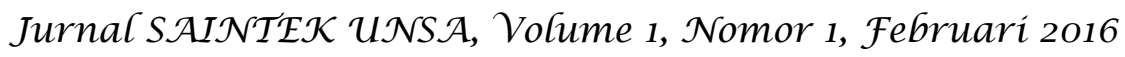

\section{B. Komponen konstruksi IPAL komunal}

1. Pemukiman Padat

Rumah adalah tempat untuk tumbuh dan berkembang, baik secara jasmani, rohani dan sosial. Definisi ini membawa banyak konsekuensi yakni bahwa selain kualitas rumah yang harus baik, diperlukan pula segala fasilitas yang dibutuhkan tumbuh dan berkembang.

2. Analisis

Analisis adalah suatu kemampuan untuk menjabarkan materi atau objek kedalam komponen-komponen, tetapi masih dalam suatu struktur organisasi tersebut, dan masih ada kaitannya satu sama lain ( Notoatmodjo, 2005 ).

3. Konstruksi

Pengertian "konstruksi" adalah suatu kegiatan membangun sarana maupun prasarana yang meliputi pembangunan gedung (building construction), pembangunan prasarana sipil (civil engineer), dan instalasi mekanikal dan elektrikal (Trianto, 2011:1).

C. Pemilihan lokasi IPAL komunal

Penetapan lokasi pembangunan konstruksi IPAL komunal dilakukan melalui 2 (dua) tahap yaitu:

1. Daftar panjang/longlist

Pemilihan lokasi dimulai dengan penetapan calon lokasi penerima DAK SLBM oleh Pemerintah Kabupaten/Kota dalam bentuk daftar panjang ( longlist ) Kelurahan.

2. Daftar pendek/shortlist

Daftar pendek merupakan data primer yang ditentukan berdasarkan hasil survei dan identifikasi daftar panjang (longlist) yang dilakukan oleh TFL dan dinas penaggung jawab kegiatan DAK SLBM berdasarkan kriteria kelayakan maksimal. 


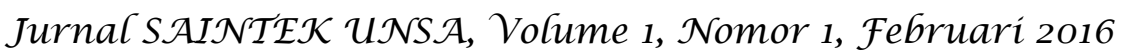

D. Bagan alir konstruksi IPAL komunal

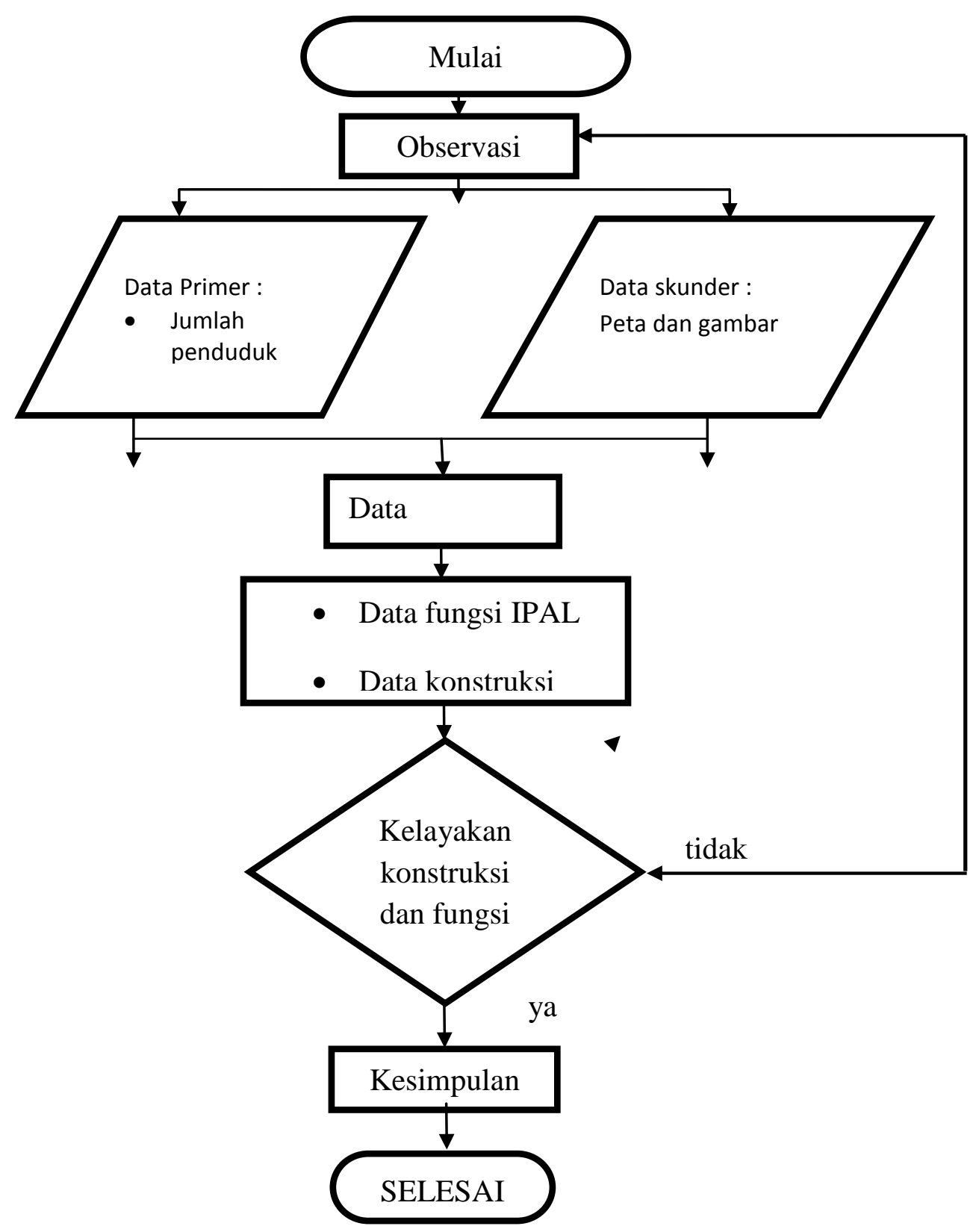

Gambar 1. Skema Penelitian 


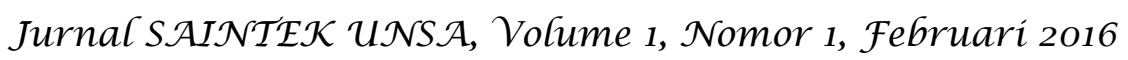

\section{E. HASIL ANALISIS DATA KONSTRUKSI IPAL}

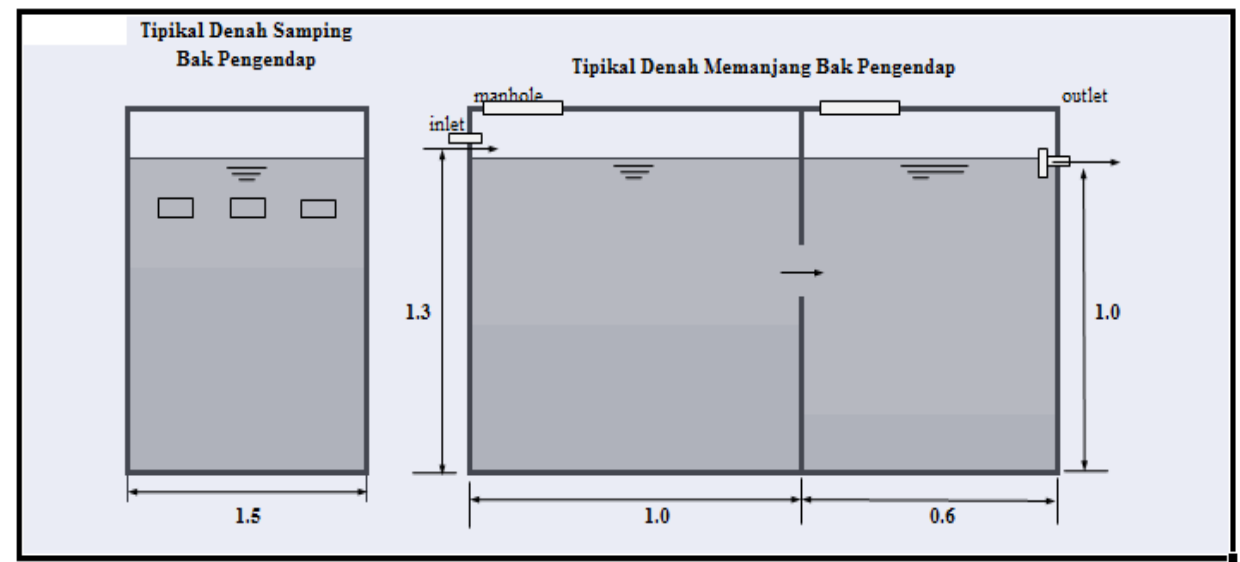

Bak Settler.

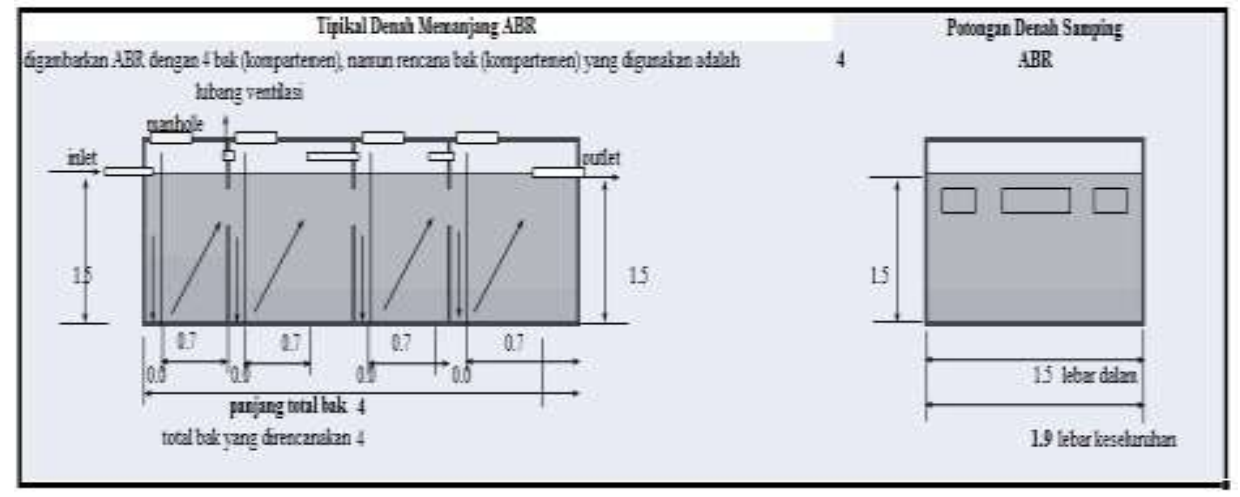

Bak ABR.

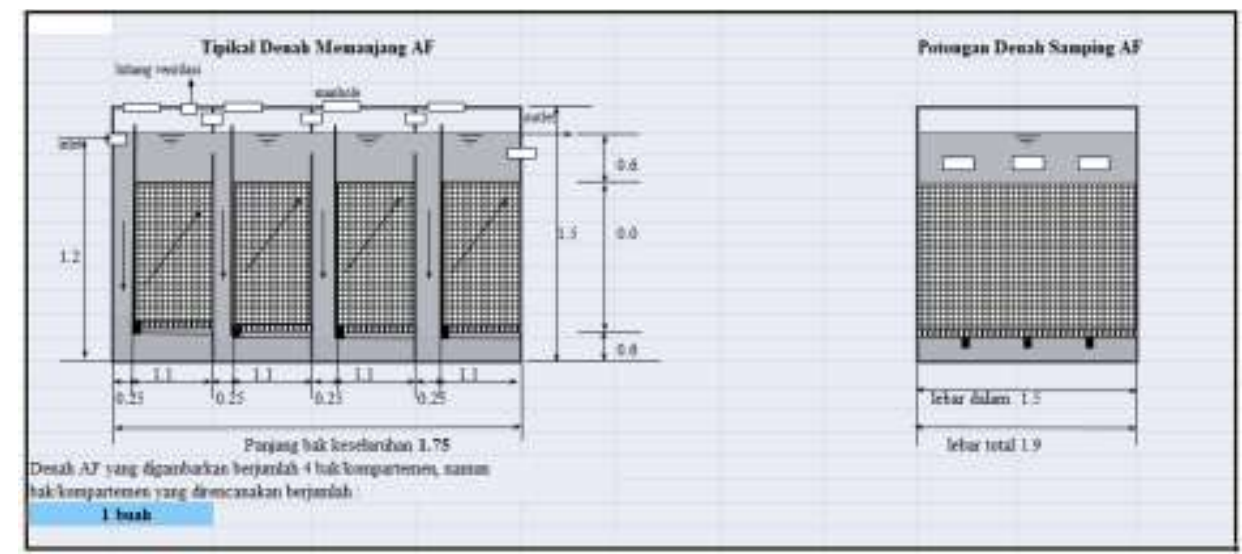

Bak AF.

Gambar 4.3 Desain konstruksi IPAL komunal 2012 kelurahan Brang Bara.

File Borda Blitz 2012. 


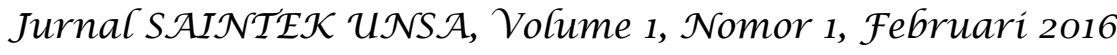

1. Proyeksi jumlah dan kepadatan penduduk

$$
\begin{aligned}
P n & =P o(1+r)^{n} \\
& =178(1+2 \%)^{10} \\
& =178(1+0,02) \\
& =178(1,02)^{10} \\
& =178 \times 1.21899 \\
& =216.98
\end{aligned}
$$

Jadi proyeksi penduduk RT 04 untuk tahun 2022 dengan tingkat pertimbangan penduduk $2 \%$ / tahun adalah 216.98 jiwa.

1. Proyeksi debit air limbah

$$
\begin{aligned}
Q & =\frac{\text { qxp }}{1000} \\
& =\frac{3560 \times 217}{1000} \\
& =\frac{772520}{1000} \\
& =772,52 \text { liter/hari }
\end{aligned}
$$

2. Proyeksi luas area IPAL komunal

$$
\begin{aligned}
T & =\frac{\mathrm{v}}{\mathrm{Q}} \\
& =\frac{79 \mathrm{~cm}}{17,1 \mathrm{~m}^{3}} \\
& =4,61 \mathrm{~m}^{3}
\end{aligned}
$$

Jadi proyeksi luas area IPAL komunal RT 04 untuk tahun 2022 dengan tingkat pertimbangan penduduk $2 \%$ / tahun adalah 192 jiwa. Di mana area yang di butuhkan untuk kontruksi IPAL sebagai berikut :

$$
\begin{aligned}
A & =\frac{T Q X 2.472 E-02}{d} \\
& =\frac{4.61 \times 2.472 \mathrm{E}-02}{2.5 \mathrm{~m}} \\
& =\frac{11,39-02}{2.5 \mathrm{~m}}
\end{aligned}
$$




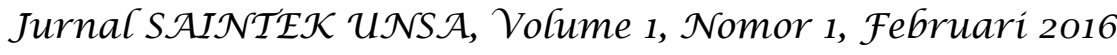

$$
\begin{aligned}
& =\frac{9,39}{2.5 \mathrm{~m}} \\
& =3.756 \mathrm{~m}^{2}
\end{aligned}
$$

Jadi area yang di butuhkan untuk kontruksi IPAL komunal RT 04 untuk tahun 2022 dengan tingkat pertimbangan penduduk $2 \%$ / tahun adalah 5,21 $\mathrm{m}^{2}$.

3. Disain teknik ipal komunal

Kapasitas disain yang direncanakan :

Kapasitas pengelolahan $\quad: 17,1 \mathrm{~m}^{3} /$ hari

$$
\begin{aligned}
& : \text { 4,61 } \mathrm{m}^{3} \\
& : \text { 772,44 liter/menit }
\end{aligned}
$$

Kriteria perencanaan $\quad:$ retention time $= \pm 24$ jam

\section{Debit Air limbah :}

1. Jumlah pemamfaat : 216.98 jiwa

2. Preentase air limbah $: 80 \%$

3. Pemakaian air bersih : $120 \mathrm{~L} / \mathrm{org} / \mathrm{hr}$

4. Debit air limbah $\quad: 772.44 \mathrm{~m}^{3} / \mathrm{hr}$

\section{Bangunan Settler:}

1. Waktu pengaliran : 24 Jam

2. Waktu pengurasan : 24 Bulan (Minimal 24 Bulan)

3. Lebar : 2,5 Meter (sesuaikan dilokasi)

4. Kedalaman : 1,7 Meter (Kedalaman Efektiv 1,5-3 meter)

5. Panjang bak 1 : 1.6 Meter

6. Panjang bak $2 \quad: 0.8$ Meter

\section{CEK!!!!!!!}

1. Volume Settler yang diperlukan : $4.41 \mathrm{~m}^{3}$

2. Volume Settler aktual $\quad: 10.2 \mathrm{~m}^{3}$

\section{Bangunan ABR:}
1. Waktu Pengaliran
: 24 jam
2. Lebar
: 2.5 Meter
3. Kedalaman
: 2.3 Meter 
Jurnal S AIN $\mathcal{N}$ EK $\mathcal{K}$ UNS A, Volume 1, Nomor 1, Februari 2016

4. Panjang

$\%$ dari kedalaman )

5. Jumlah kompartemen

CEK!!!!!!

6. Kecepatan aliran keatas

7. HRT

\section{Bangunan AF:}

1. Waktu pengaliran

2. Lebar

3. Kedalaman

4. Panjang

5. Jumlah kompartemen

6. Tinggi media

7. Luas media filter

8. Rongga dalam media filter CEK!!!!!!!

9. Kecepatan dalam rongga filter 10. HRT
: 0.8 Meter ( panjang efektiv 50-60

: 4 Unit

: $0.43 \mathrm{~m} / \mathrm{jam}(0.6-2 \mathrm{~m} / \mathrm{jam})$

: 20 jam

: 24 jam

: 2.5 meter

: 2.5 meter

: 1.3 meter

: 1 Unit

: 1.2 Meter

$: 100 \mathrm{~m}^{2} / \mathrm{m}^{3}(80-120)$

: $40 \%(30-45 \%)$

: $0.67 \mathrm{~m} / \mathrm{jam}$ ( $0.6 \mathrm{~m} / \mathrm{jam}$ )

: 0,67 jam ( 24-48 jam )

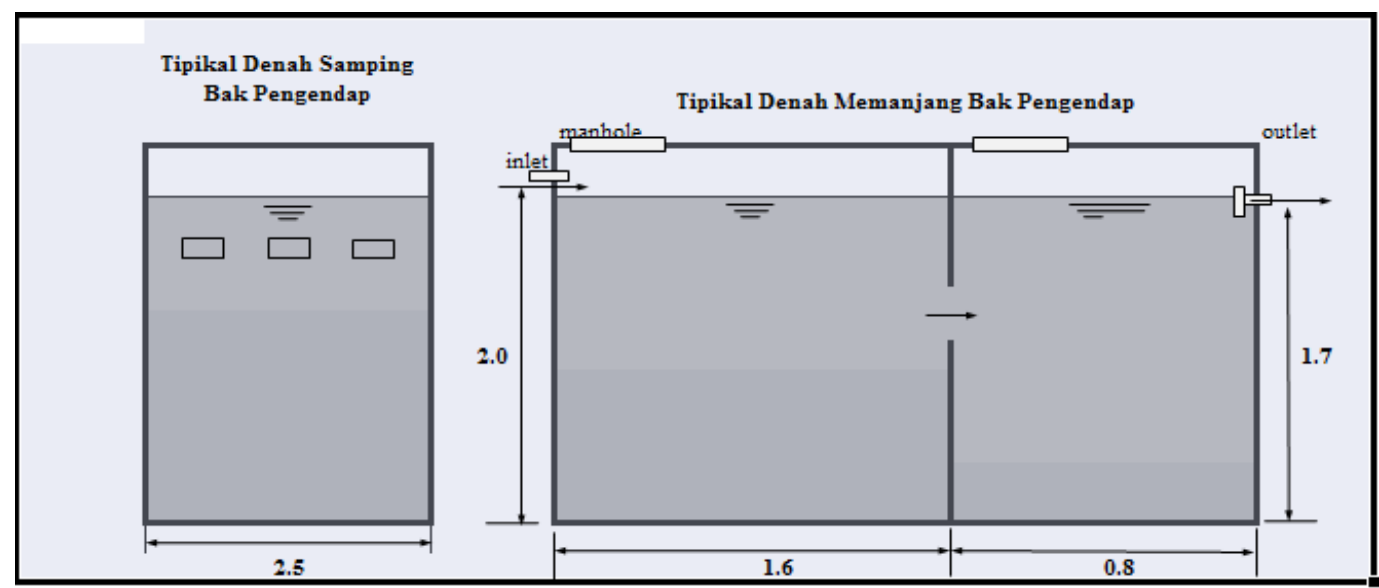

Bak settler. 


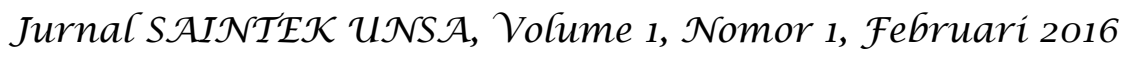

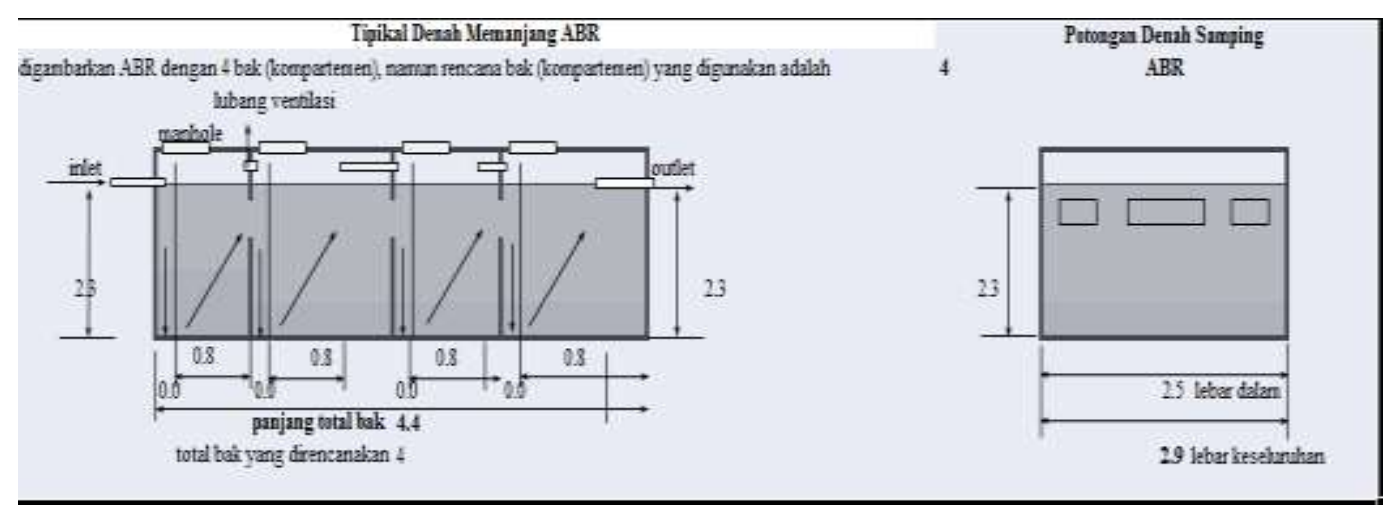

Bak ABR

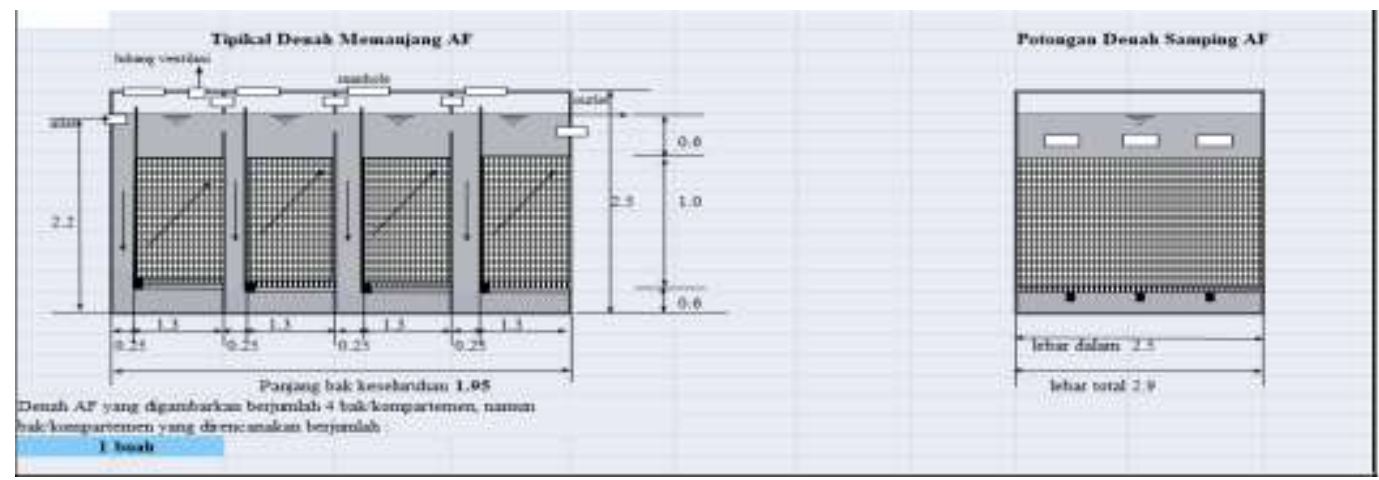

\section{Bak AF}

Gambar 4.4 Redesain konstruksi IPAL komunal 2015 kel. Brang Bara. Isra junna Borda Blitz 2015.

Tabel 3.2 Hasil analisis konstruksi IPAL komunal tahun 2012-2022. 


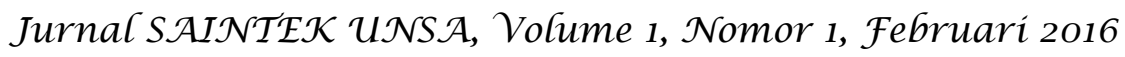

\begin{tabular}{|c|c|c|c|c|c|c|c|c|c|c|c|c|c|c|c|c|c|c|c|}
\hline \multirow{2}{*}{ Inter } & \multirow{2}{*}{ Iming } & \multirow{2}{*}{$\begin{array}{c}\text { Deir } \\
\text { Ait } \\
\text { liahes }\end{array}$} & \multicolumn{2}{|c|}{ xist } & \multicolumn{4}{|c|}{ Feecuen Sarix. } & \multicolumn{4}{|c|}{ Anesen ABQ. } & \multicolumn{7}{|c|}{ Bugna $A F$} \\
\hline & & & 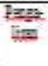 & 觜 & I & 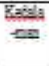 & $\begin{array}{l}\text { Pring } \\
\text { BARI }\end{array}$ & $\begin{array}{l}\text { Prieg } \\
\text { Bar? }\end{array}$ & t & 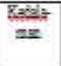 & p & besitene & I & 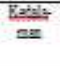 & p & inin & 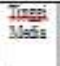 & 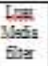 & 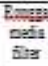 \\
\hline $\begin{array}{l}2012- \\
2013\end{array}$ & 185.19 & $\begin{array}{c}17 \pi \\
\mathrm{m} 3 / \\
\mathrm{H}\end{array}$ & 24 & 24 & $\frac{1.5}{m}$ & $\begin{array}{c}10 \\
\mathrm{~m}\end{array}$ & $\begin{array}{l}10 \\
\mathrm{~m}\end{array}$ & $\begin{array}{c}0.6 \\
\mathrm{~m}\end{array}$ & $\begin{array}{l}1.5 \\
m\end{array}$ & $\begin{array}{c}15 \\
\mathrm{~m}\end{array}$ & $\begin{array}{c}0.7 \\
\mathrm{~m}\end{array}$ & 4 unit & $\begin{array}{c}15 \\
\mathrm{~m}\end{array}$ & $1.5 \mathrm{~m}$ & $\begin{array}{c}11 \\
\mathrm{~m}\end{array}$ & 1 unit & $\begin{array}{l}0.8 \\
\mathrm{~m}\end{array}$ & $\begin{array}{l}100 \\
\mathrm{~m} 2 / \\
\mathrm{m} 3\end{array}$ & $40 \%$ \\
\hline $\begin{array}{l}2012- \\
2014\end{array}$ & 188.85 & $\begin{array}{c}1813 \\
\mathrm{~m} 3 / \\
\mathrm{H}\end{array}$ & 24 & 24 & $\begin{array}{l}1.6 \\
m\end{array}$ & $\begin{array}{l}1.5 \\
\mathrm{~m}\end{array}$ & $\begin{array}{l}11 \\
\mathrm{~m}\end{array}$ & $\begin{array}{c}0.7 \\
\mathrm{~m}\end{array}$ & $\begin{array}{l}1.5 \\
m\end{array}$ & $\begin{array}{l}15 \\
\mathrm{~m}\end{array}$ & $\begin{array}{l}0.7 \\
\mathrm{~m}\end{array}$ & 4 unit & $\begin{array}{c}15 \\
\mathrm{~m}\end{array}$ & $\begin{array}{l}15 \\
\mathrm{~m}\end{array}$ & $\begin{array}{c}11 \\
\mathrm{~m}\end{array}$ & 1 unit & $\begin{array}{l}0.8 \\
\mathrm{~m}\end{array}$ & $\begin{array}{l}100 \\
\mathrm{~m} 2 / \\
\mathrm{m} 3\end{array}$ & $40 \%$ \\
\hline $\begin{array}{l}2012- \\
2015\end{array}$ & 192.67 & $\begin{array}{c}18.49 \\
\mathrm{~m} 3 / \\
\mathrm{H}\end{array}$ & 24 & 24 & $\frac{1.8}{m}$ & $\begin{array}{l}1.5 \\
\mathrm{~m}\end{array}$ & $1.3 \mathrm{~m}$ & $0.7 \mathrm{~m}$ & $\begin{array}{l}1.5 \\
\mathrm{~m}\end{array}$ & $1.5 \mathrm{~m}$ & $\begin{array}{c}0.7 \\
\mathrm{~m}\end{array}$ & 4 unit & $\begin{array}{c}1.5 \\
\mathrm{~m}\end{array}$ & $1.5 \mathrm{~m}$ & $\begin{array}{c}1.3 \\
\mathrm{~m}\end{array}$ & 1 unit & $\begin{array}{l}0.8 \\
\mathrm{~m}\end{array}$ & $\begin{array}{l}100 \\
\mathrm{~m} 2 / \\
\mathrm{m} 3\end{array}$ & $40 \%$ \\
\hline $\begin{array}{c}2012- \\
2022\end{array}$ & 216.98 & $\begin{array}{l}772.5 \\
2 \mathrm{~L} / \mathrm{H}\end{array}$ & 24 & 24 & $\begin{array}{c}2.5 \\
\mathrm{~m}\end{array}$ & $\begin{array}{c}1,85 \\
\mathrm{~m}\end{array}$ & $1.6 \mathrm{~m}$ & $0.8 \mathrm{~m}$ & $\begin{array}{c}2.5 \\
\mathrm{~m}\end{array}$ & $23 \mathrm{~m}$ & $\begin{array}{c}0.8 \\
m\end{array}$ & 4 Unit & $\begin{array}{c}25 \\
m\end{array}$ & $25 \mathrm{~m}$ & $\begin{array}{c}13 \\
\mathrm{~m}\end{array}$ & 1 Unit & $1.2 \mathrm{~m}$ & $\begin{array}{l}100 \\
\mathrm{~m} 2 / \\
\mathrm{m} 3\end{array}$ & $40 \%$ \\
\hline
\end{tabular}

\section{KESIMPULAN}

Berdasarkan hasil pembahasan dan analisis serta merujuk pada tujuan penelitian maka dapat disimpulkan beberapa hal sebagai berikut:

1) Konstruksi IPAL yang dibangun pada tahun 2012 masih kurang efisien jika dianalisis secara teknis.

2) Dari analisis yang dilakukan terhadap IPAL komunal harus dilakukan Redesain agar pengoperasian IPAL komunal berjalan optimal.

3) Hasil dari Redesain yang dilakukan pada IPAL komunal menunjukan bahwa terjadi perpindahan konstruksi bangunan IPAL komunal 35 meter keselatan dari konstruksi awal dan elevasi berubah dari 10 meter dari permukaan air laut menjadi 6 meter diatas permukaan air laut dan didukung dengan letak geografis kelurahan brang bara yang berada pada ketinggian berkisar 0 hingga 30 meter diatas permukaan air laut.

4) Analisis IPAL komunal yang dilakukan dari tahun 2012-2022 menunjukan bahwa bak Settler yang dulunya 1 meter bak pertama dan 0.6 meter bak kedua diubah menjadi 1.6 meter bak pertama dan 0.8 bak kedua, desain bak ABR yang dulunya 0.7 meter diubah menjadi 0.8 meter dan jumlah 


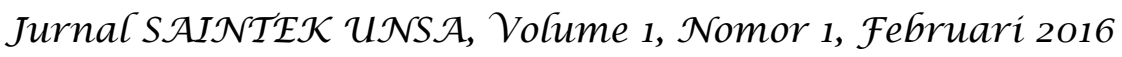

kompartemen masih tetap sama yaitu 4 bak, desain bak AF yang dulunya 1.1 meter diubah menjadi 1.3 meter, Jadi desain IPAI komunal tahun 2012 setelah dianalisis ulang sampai tahun 2022 mendapat perubahan yang sangat signifikan baik dari lokasi yang dulunya dibantaran sungai dipindahkan 35 meter keselatan Bangunan konstruksi awal, konstruksi IPAL yang jumlah debit air limbahnya sebesar $20.83008 \mathrm{~m}^{3}$ /hari sampai tahun 2022.

\section{DAFTAR PUSTAKA}

Agus .S, (2010), Model Pendekatan Geografi Guna Menganalisis Permasalahan Lingkungan, Makalah. Yogyakarta.

Abdul Wahab, Solichin. 2008. Pengantar Analisis Kebijakan Publik. Malang: UMM Press.

Alaerts, S. (1984) : Metode Penelitian Air, Usaha Nasional, Surabaya

A.G. Subarsono, Analisis Kebijakan Publik, Yogyakarta, Pustaka Pelajar, 2008

Bintarto. (1977), Buku Penuntun Geografi Sosial. Yogyakarta : Up Spring

Departemen Pekerjaan Umum, Dirjen Cipta Karya, (1999), Petunjuk Teknis Perencanaan Pembangunan dan Pengelolaan Bidang ke PLP-an di Perkotaan dan Perdesaan, Jakarta.

De. Kruijff,G. J. W. (1987), Rencana Sistem Tangki septik, UNDP INS/84/005, Jakarta.

Direktorat Jenderal Ciptakarya PU. (2006). Dasar-dasar Teknik dan Pengelolaan Air Limbah. Buku Pedoman. Direktorat Pengembangan Penyehatan Lingkungan Permukiman. Jakarta.

Halverson, N.V. (2004). Review of Constructed Subsurface Flow vs. Surface Flow Wetlands. Journal of Westinghouse Savannah River Site, US Department of Energy. WSRC-TR-2004-00509

Notoatmodjo,s. 2005. Metodologi penelitian kesehatan. Jakarta : PT Rineka Cipta Pedrero, F., Albuquerque, A., Monte, H.M.do., Cavaleiro, V., and Alarcon, J.J. (2011). Application of GIS-based multi-criteria analysis for site selection of aquifer recharge with reclaimed water. Journal of Conservation and Recycling. 56:105-116.

Purnama, A, 2011. STUDI KELAYAKAN PEMBANGUNAN PEMBANGKIT LISTRIK TENAGA MIKROHIDRO Studi Kasus: PLTMH Minggir pada saluran irigasi Minggir di Padukuhan Klagaran Desa Sendangrejo Kecamatan Minggir Kabupaten Sleman, Jurnal Unsa Progress. Vol.10, No.15, Oktober, Universitas Samawa, Sumbawa Besar.

Purnama, A., Nuraini, E, dan Saputri, D. E. 2016. STUDI KELAYAKAN SALURAN DRAINASE JALAN SULTAN KAHARUDDIN KM. 02 KABUPATEN SUMBAWA, Jurnal Saintek Unsa. Vol.1, No.1, Februari, Universitas Samawa, Sumbawa Besar. 


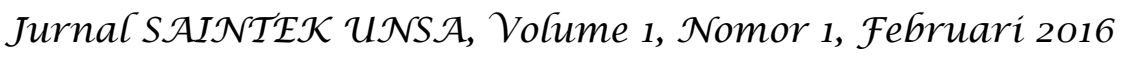

Rhomaidi. (2004). Pengelolahan Sanitasi Secara Terpadu Sungai Widuri : Studi Kasus Kampung Niti Praya Yogyakarta : Skripsi Tehnik Lingkungan Fakultas Tehnik Sipil dan Perencanaan Universitas Islam Indonesia.

Rifai, A. dan Nugroho, R. (2007). Kajian Pendahuluan Kelayakan Penerapan Instalasi Pengolahan Air Limbah Domestik Secara Komunal di Permukiman Kota Bogor. JAI Volume 3, No.2.

Suparman dan Suparmin. (2002), Pembuangan Tinja dan Limbah Cair, Penerbit Buku Kedokteran EGC, Jakart

suharyono, Moch Amien, (1994). Seminar Loka karya di semarang tahun 1988.

Semarang. 